\title{
Prevalence of Major Comorbidities in Chronic Obstructive Pulmonary Disease Caused by Biomass Smoke or Tobacco
}

\author{
Rafael Golpe Irene Martín-Robles Pilar Sanjuán-López Esteban Cano-Jiménez \\ Olalla Castro-Añon Noemí Mengual-Macenlle Luis Pérez-de-Llano
}

Servicio de Neumología, Hospital Universitario Lucus Augusti, Lugo, Spain

\section{Keywords}

Chronic obstructive pulmonary disease - Biomass - Tobacco . Comorbidity · Cardiovascular risk factors · Coronary artery disease

\begin{abstract}
Background: Comorbidities are very common in chronic obstructive pulmonary disease (COPD), contributing to the overall severity of the disease. The relative prevalence of comorbidities in COPD caused by biomass smoke (B-COPD), compared with COPD related to tobacco (T-COPD), is not well known. Objectives: To establish if both types of COPD are associated with a different risk for several major comorbidities. Method: The prevalence of comorbidities was compared in 863 subjects with B-COPD ( $n=179,20.7 \%)$ or TCOPD ( $n=684,79.2 \%$ ). Multivariate analysis was carried out to explore the independent relationship between comorbidities and type of exposure. Results: Three comorbidities were more frequent in T-COPD than in B-COPD: ischemic heart disease (11.5 vs. 5.0\%, respectively, $p=0.01$ ), peripheral vascular disease ( 9.2 vs. $2.7 \%, p=0.006$ ), and peptic ulcer disease ( $4.8 \%$ vs. $0, p=0.005)$. After correcting for potential confounding variables, the risk of ischemic heart disease was lower in B-COPD than in T-COPD (OR: 0.33, 95\% Cl: 0.16-0.69,
\end{abstract}

(C) 2017 S. Karger AG, Basel $p=0.003)$. Conclusions: The prevalence of ischemic heart disease is significantly lower in B-COPD than in T-COPD, suggesting a different systemic effect of both types of smoke in COPD patients.

(c) 2017 S. Karger AG, Basel

\section{Introduction}

Chronic obstructive pulmonary disease (COPD) is a leading cause of mortality and morbidity worldwide. Unlike other common causes of death, there has been an upward trend in mortality due to COPD. The World Health Organization projected that total deaths from the disease will increase in the next years, and COPD is estimated to become the third leading cause of death worldwide in 2030 [1]. Comorbidities are very common in COPD, and they contribute to the overall severity of the disease, impairing quality of life and increasing mortality [2-4]. The prevalence of the different comorbidities in COPD varies according to several variables, like gender, severity of the ventilatory impairment, or predominant COPD phenotype $[5,6]$.

Although cigarette smoking is the main risk factor for COPD in developed countries, indoor air pollution asso- 
ciated with biomass burning is also a significant risk factor for the disease [7]. COPD caused by biomass smoke (B-COPD) differs from COPD related to tobacco (TCOPD), for example, it has a slower decline of $\mathrm{FEV}_{1}$ and a different distribution of phenotypes [8-10]. However, there are few data regarding the prevalence of comorbidities in both disease types.

The association between COPD and several comorbidities may be related to common genetic predisposition or to shared lifestyle or environmental risk factors. However, there is also the possibility of a pathogenic connection between COPD and the different comorbid conditions. COPD is nowadays considered an inflammatory disease, and systemic inflammation is probably the key for linking COPD and several diseases [11]. The systemic inflammatory response induced by exposure to biomass smoke seems to differ from that caused by tobacco, and B-COPD patients might develop a Th2-type inflammatory response [12]. Therefore, it is plausible that the biologic effects differ between both types of smoke, and that this might result in a different prevalence of comorbidities in B-COPD and T-COPD.

Our hypothesis was that the prevalence of several major comorbidities would be different in B-COPD and TCOPD, and that the differences would persist after correcting for potential confounding variables.

\section{Methods}

\section{Study Design and Subjects}

This is part of a retrospective study aimed at evaluating clinical differences between patients with B-COPD and T-COPD. The setting was the COPD clinic of a university hospital that provides community health services to 220,000 individuals living mainly in rural areas, where biomass fuels (wood smoke) have been traditionally used for cooking and heating. The study was approved by our ethical committee (Comité Ético de Investigación Clínica de Galicia, registry code: 2012/132). All consecutive patients evaluated at the COPD clinic between February 2009 and October 2016 were considered for inclusion in the study. Subjects were selected for the study from a prospectively collected database of COPD patients, which was analyzed retrospectively. Inclusion criteria were a diagnosis of COPD based on the GOLD initiative [2]. Exclusion criteria were alfa-1-antitrypsin deficiency, human immunodeficiency virus infection, concomitant diagnosis of other significant respiratory diseases (i.e., pulmonary fibrosis, pneumoconiosis, lung parenchymal disease due to previous tuberculosis), and exposure to inhaled drugs or other fumes different to biomass smoke or tobacco. Subjects were classified into 2 groups: T-COPD (smoking background, with a pack-year index greater than 10) and BCOPD (a history of at least 20 years of exposure to biomass smoke that began in youth age, in never smokers) [10]. Due to the retrospective design of the study, the cumulative exposure to biomass smoke could not be calculated precisely. Smoke exposure varied significantly overtime. Many patients were exposed during their childhood and youth to environmental smoke from the traditional kitchens ("lareiras") used in our region (open fires in a fireplace). These kitchens produce much more home pollution than the more modern biomass ovens and stoves that have replaced them in recent decades. Moreover, because biomass was used also as a home heating system, smoke exposure was significantly higher in the winter months than during the rest of the year and varied from year to year with changing climatic conditions. Therefore, it was not possible to accurately estimate the intensity of biomass smoke exposure, which was coded as a categorical variable (present/absent). For the purposes of the study, subjects with a history of smoking were assigned to the T-COPD group even if there was a remote history of exposure to biomass smoke. The subjects were classified into 3 mutually exclusive phenotypes, according to a modification of the Spanish COPD guidelines [13]: (1) chronic bronchitis: cough and sputum production for at least 3 months in 2 consecutive years; (2) emphysema: absence of chronic sputum production and either reduced CO diffusion (TLCO/VA $<80 \%$ ) or radiologic evidence of emphysema; and (3) asthma-COPD overlap syndrome (ACOS): 2 major criteria or 1 major criterion and 2 minor criteria, as specified elsewhere [10]. Furthermore, all patients were classified as frequent or infrequent exacerbators. Frequent exacerbators were defined as those who suffered at least 2 exacerbations requiring treatment with antibiotics or corticosteroids (or both) over the year prior to the first visit to the COPD clinic [14].

\section{Comorbidities}

According to the usual procedures of the COPD clinic, presence or absence of the comorbidities included in the Charlson index [15] and the COPD-specific comorbidity index (COTE) [16] were systematically registered because the diseases included in those indices have been found to have a prognostic significance in COPD. Thus, the following comorbidities were selected and recorded for all patients at the time of the first visit: coronary artery disease, heart failure, peripheral vascular disease, cerebrovascular disease, diabetes, chronic renal failure, peptic ulcer disease, solid neoplasms, leukemia, lymphoma, anxious depressive syndrome, atrial fibrillation, collagen disease, and liver disease. The presence of each comorbidity was confirmed through a comprehensive review of the computerized medical records, results of diagnostic procedures, and therapies specific to any disease. Self-reported diagnoses were not recorded. The non-age-adjusted Charlson index and the COTE index were calculated for every patient. Comorbidities not included in the Charlson or COTE indices were not considered.

\section{Statistical Analysis}

Normal distribution of data was assessed using the D'Agostino Pearson test. Between-groups comparisons for continuous variables were made using the Student $t$ test or the Mann-Whitney test, as appropriate. The $\chi^{2}$ test was used for categorical variables. A 2 -tailed $p$ value $<0.05$ was considered significant. When the prevalence of comorbidities was significantly different for the B-COPD and T-COPD groups, a multivariate logistic regression analysis was carried out by means of a stepwise backward selection. The dependent variable in the multivariate analysis was the diagnosis of the comorbidity. We selected as independent (explanatory) variables those variables with a previously reported association in the medical literature (age [17], gender [5], severity of COPD [5,

Comorbidities in Biomass COPD 
Fig. 1. Prevalence of comorbidities in the biomass and tobacco groups. IHD, ischemic heart disease; $\mathrm{CHF}$, chronic heart failure; PVD, peripheral vascular disease; CD, cerebrovascular disease; $\mathrm{AF}$, atrial fibrillation; $\mathrm{PU}$, peptic ulcer disease; $\mathrm{DM}$, diabetes mellitus; CRF, chronic renal failure; ST, solid tumor; LL, leukemia or lymphoma; ADS, anxious depressive syndrome; CD, collagen disease; LD, liver disease.

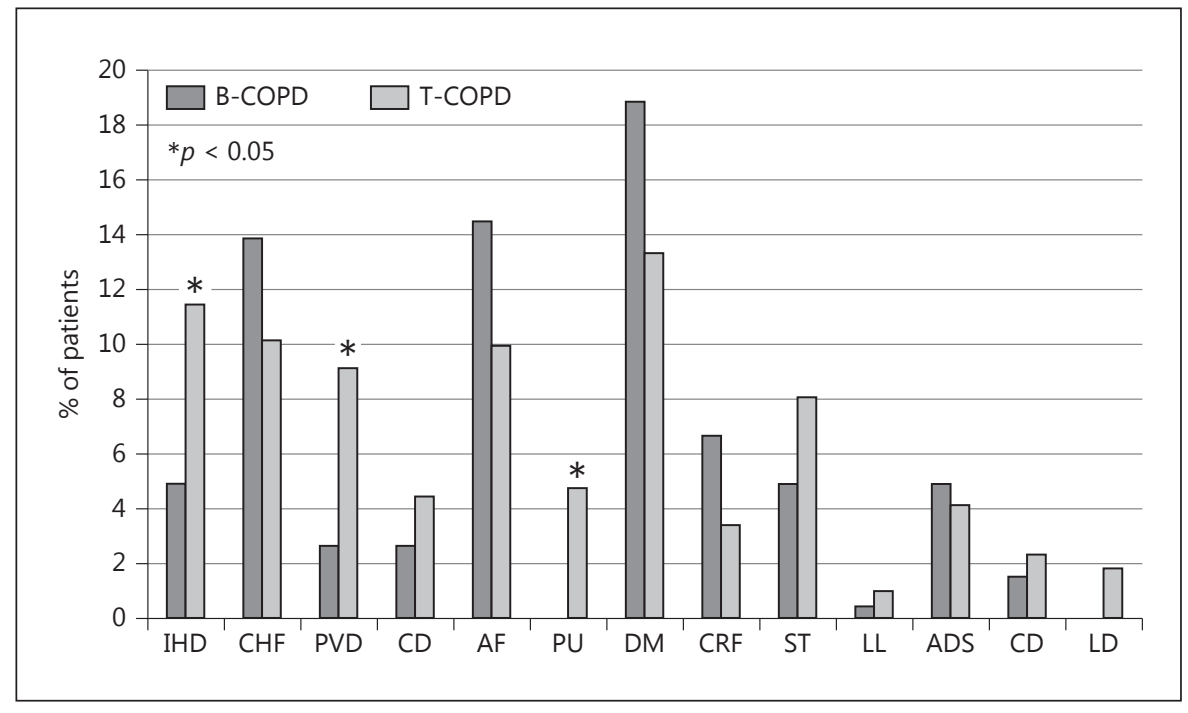

6], and clinical phenotype [6]) or with biological plausibility of an association (frequent COPD exacerbations and the type of smoke exposure, which was the basis for the working hypothesis). Age was coded in 1-year increments. Clinical phenotypes and biomass exposure were coded as dichotomous variables (present/absent). Lung function was coded using the ordinal (1-4) GOLD stage of severity of ventilatory obstruction [2]. Goodness of fit was assessed using the Hosmer-Lemeshow test. Multicollinearity was ruled out by checking the variance inflation factor values. Since this is a retrospective study, and the study population included all patients seen at the COPD clinic, the sample size for this analysis was not calculated beforehand. The statistical power of the study was calculated to detect differences between B-COPD and T-COPD [18].

\section{Results}

A total of 863 patients were included in the study, 179 (20.7\%) with B-COPD and 684 (79.2\%) with T-COPD. Table 1 compares the characteristics between both groups. B-COPD patients were older, there were less male subjects in this group, and the body mass index, lung function variables, and peripheral oxygen saturation were higher. There was an uneven distribution of clinical phenotypes between both groups, as reported earlier [10], but the percentages of frequent exacerbators were similar for both types of exposure. $\mathrm{FEV}_{1} \%$ was significantly lower for males than for females $(49.2 \pm 16.9$ vs. $56.7 \pm 15.3 \%$, respectively, $p<0.0001)$.

The values of the non-age-adjusted Charlson comorbidity index were similar for B-COPD and T-COPD (1.78 \pm 1.22 vs. $2.00 \pm 1.43$, respectively, $p=0.06)$. There were no differences between groups in the values of the COTE index $(1.05 \pm 1.80$ vs. $1.04 \pm 1.69$, respectively, $p=0.56)$.
Table 1. Differences between the biomass and tobacco groups

\begin{tabular}{|c|c|c|c|}
\hline Variable & $\begin{array}{l}\text { B-COPD } \\
(n=179)\end{array}$ & $\begin{array}{l}\text { T-COPD } \\
(n=684)\end{array}$ & $p$ \\
\hline Age, years & $73.7 \pm 8.0$ & $68.4 \pm 9.6$ & $<0.0001$ \\
\hline Males, $n$ & $77(43.0)$ & $615(89.9)$ & $<0.0001$ \\
\hline BMI & $29.5 \pm 5.7$ & $28.2 \pm 5.2$ & 0.005 \\
\hline $\mathrm{SpO}_{2} \%$ & $93.7 \pm 3.7$ & $92.9 \pm 4.6$ & 0.02 \\
\hline $\mathrm{FEV}_{1} \%$ & $55.1 \pm 15.2$ & $49.5 \pm 17.1$ & 0.0001 \\
\hline FVC\% & $71.5 \pm 14.7$ & $73.7 \pm 17.3$ & 0.09 \\
\hline $\mathrm{FEV}_{1} / \mathrm{FVC} \%$ & $54.3 \pm 11.0$ & $48.5 \pm 12.4$ & $<0.0001$ \\
\hline mMRC score & $1.4 \pm 0.5$ & $1.4 \pm 0.7$ & 0.53 \\
\hline $\mathrm{CB}, n$ & $80(47.9)^{\mathrm{a}}$ & $327(49.4)^{\mathrm{a}}$ & 0.79 \\
\hline Emphysema, $n$ & $53(31.7)^{\mathrm{a}}$ & $298(45.0)^{\mathrm{a}}$ & 0.002 \\
\hline ACOS, $n$ & $34(20.3)^{\mathrm{a}}$ & $36(5.4)^{\mathrm{a}}$ & $<0.0001$ \\
\hline Frequent exacerbator, $n$ & $58(32.4)$ & $238(34.7)$ & 0.60 \\
\hline GOLD stage, $n$ & & & $<0.001$ \\
\hline 1 & $5(2.7)$ & $38(5.5)$ & \\
\hline 2 & $105(58.6)$ & $294(43.5)$ & \\
\hline 3 & $62(34.6)$ & $249(36.4)$ & \\
\hline 4 & 7 (3.9) & $103(15.0)$ & \\
\hline
\end{tabular}

Values in parentheses are percentages. BMI, body mass index; $\mathrm{SpO}_{2}$, peripheral oxygen saturation; $\mathrm{mMRC}$, modified medical research council; $\mathrm{CB}$, chronic bronchitis; ACOS, asthma-COPD overlap syndrome.

a Only 167 B-COPD and 661 T-COPD subjects could be classified according to clinical phenotypes.

Figure 1 and Table 2 compare the relative prevalence of comorbidities between both groups. Ischemic heart disease, peripheral vascular disease, and peptic ulcer disease were significantly more prevalent in the T-COPD group,
Golpe et al. 
Table 2. Prevalence of comorbidities for both study groups

\begin{tabular}{lccl}
\hline Comorbidity & $\begin{array}{c}\text { B-COPD } \\
(n=179)\end{array}$ & $\begin{array}{c}\text { T-COPD } \\
(n=684)\end{array}$ & $p$ \\
\hline $\begin{array}{lcc}\text { Ischemic heart disease } \\
\text { Chronic heart failure }\end{array}$ & $95(5.0)$ & $79(11.5)$ & 0.01 \\
$\begin{array}{l}\text { Peripheral vascular } \\
\quad \text { disease }\end{array}$ & $5(2.7)$ & $63(9.2)$ & 0.006 \\
Cerebrovascular disease & $5(2.7)$ & $31(4.5)$ & 0.38 \\
Atrial fibrillation & $26(14.5)$ & $69(10.0)$ & 0.11 \\
Any cardiovascular & & & \\
$\quad$ disease & $70(39.1)$ & $312(45.6)$ & 0.14 \\
Peptic ulcer disease & 0 & $33(4.8)$ & 0.005 \\
Diabetes mellitus & $34(18.9)$ & $92(13.4)$ & 0.08 \\
Chronic renal failure & $12(6.7)$ & $24(3.5)$ & 0.08 \\
Solid tumor & $9(5.0)$ & $56(8.1)$ & 0.21 \\
Leukemia or lymphoma & $1(0.5)$ & $8(1.1)$ & 0.76 \\
Anxious depressive & & & \\
$\quad$ syndrome & $9(5.0)$ & $29(4.2)$ & 0.79 \\
Collagen disease & $3(1.6)$ & $17(2.4)$ & 0.71 \\
Liver disease & 0 & $13(1.9)$ & 0.13 \\
\hline
\end{tabular}

Values are given as $n(\%)$.
Biomass smoke is a well-recognized cause of COPD [7]. B-COPD has been described mainly in developing countries, but biomass burning can also be a significant cause of disease in industrialized countries [19]. It is still not totally clear which are the differences between BCOPD and T-COPD, and there is not enough evidence regarding the association between $\mathrm{B}-\mathrm{COPD}$ and coexisting diseases. Individuals with COPD are substantially more likely to suffer several comorbidities [11]. Although the coincidence of COPD with other comorbidities might be the result of shared risk factors, several pathogenic mechanisms might directly link COPD with other diseases. Increased levels of inflammatory cytokines are found in COPD and this persistent, low-grade systemic inflammation might be central to the link between this disease and its dependent comorbidities, especially cardiovascular diseases $[11,20]$.

The present study has found that B-COPD patients have a lower risk of ischemic heart disease than do patients with T-COPD. There are 2 plausible explanations for this observation. Firstly, the different nature of the noxious agent (biomass or tobacco smoke) may cause a different direct effect on the coronary arteries. Secondly, there might be substantial difference in the systemic inflammatory response to biomass and tobacco smoke, as suggested by a recent study [12]. Subjects with COPD induced by biomass smoke showed higher abundance of IL-4-producing $\mathrm{T}$ helper cells (Th2) in the peripheral blood than patients with T-COPD or healthy controls. On the contrary, increased numbers of Th17 cells and higher IL-6 concentrations were found in patients with T-COPD [12]. IL-17, secreted by Th17 cells, induces production of IL-6 by several cells (like epithelial cells and airway fibroblasts). IL-6 is a proinflammatory cytokine that has been associated with a higher risk of death in COPD [21] and it might have a role in the pathogenesis of atherosclerosis [22]. IL-8, implicated in neutrophils chemotaxis and activation, was also found in higher concentrations in patients with T-COPD compared to those with B-COPD [12]. IL-8 seems to be implicated in the formation and preservation of the inflammatory environment of the damaged vascular wall, and it might have a role in cardiovascular disease [23]. Therefore, it is plausible that B-COPD and T-COPD might be associated with a different prevalence of comorbidities and that $\mathrm{T}$ COPD might be related with a higher risk of cardiovascular disease.

It must be pointed out that the inflammatory response might vary with different types of biomass fuels. Animal models showed that mice subchronically exposed to cow

Respiration 2017;94:38-44 DOI: $10.1159 / 000472718$

Comorbidities in Biomass COPD 
Table 3. Univariate and multivariate logistic regression analysis for ischemic heart disease

\begin{tabular}{|c|c|c|c|c|c|c|}
\hline \multirow[t]{2}{*}{ Variable } & \multicolumn{3}{|c|}{ Univariate analysis } & \multicolumn{3}{|c|}{ Multivariate analysis } \\
\hline & OR & $95 \% \mathrm{CI}$ & $p$ & OR & $95 \% \mathrm{CI}$ & $p$ \\
\hline Age & 1.04 & $1.01-1.06$ & 0.002 & 1.05 & $1.02-1.07$ & $<0.01$ \\
\hline Male sex & 2.44 & $1.20-4.95$ & 0.01 & $-{ }^{\mathrm{a}}$ & $-{ }^{\mathrm{a}}$ & $-{ }^{\mathrm{a}}$ \\
\hline Biomass exposure & 0.40 & $0.19-0.82$ & 0.01 & 0.33 & $0.16-0.69$ & 0.003 \\
\hline CB phenotype & 1.21 & $0.77-1.88$ & 0.39 & $-{ }^{\mathrm{a}}$ & $-{ }^{\mathrm{a}}$ & $-{ }^{\mathrm{a}}$ \\
\hline Emphysema phenotype & 1.09 & $0.69-1.70$ & 0.69 & $-^{\mathrm{a}}$ & $-^{\mathrm{a}}$ & $-^{\mathrm{a}}$ \\
\hline ACOS phenotype & 0.22 & $0.05-0.95$ & 0.04 & $-{ }^{\mathrm{a}}$ & $-{ }^{\mathrm{a}}$ & $-{ }^{\mathrm{a}}$ \\
\hline Frequent exacerbator phenotype & 1.60 & $1.02-2.50$ & 0.03 & $-^{\mathrm{a}}$ & $-^{\mathrm{a}}$ & $-^{\mathrm{a}}$ \\
\hline GOLD stage & 0.89 & $0.67-1.20$ & 0.46 & $--^{\mathrm{a}}$ & $-^{\mathrm{a}}$ & $-^{\mathrm{a}}$ \\
\hline
\end{tabular}

$\mathrm{CB}$, chronic bronchitis; ACOS, asthma-COPD overlap syndrome.

a Variables not included in the final model.

Table 4. Univariate and multivariate logistic regression analysis for peptic ulcer disease

\begin{tabular}{|c|c|c|c|c|c|c|}
\hline \multirow[t]{2}{*}{ Variable } & \multicolumn{3}{|c|}{ Univariate analysis } & \multicolumn{3}{|c|}{ Multivariate analysis } \\
\hline & OR & $95 \%$ CI & $p$ & OR & $95 \% \mathrm{CI}$ & $p$ \\
\hline Age & 1.02 & $0.98-1.06$ & 0.27 & $-^{\mathrm{a}}$ & $-^{\mathrm{a}}$ & $--^{\mathrm{a}}$ \\
\hline Male sex & 5.57 & $1.23-25.1$ & 0.02 & 5.52 & $1.15-26.44$ & 0.03 \\
\hline Biomass exposure & 0.48 & $0.16-1.38$ & 0.17 & $-^{\mathrm{a}}$ & $-^{\mathrm{a}}$ & $--^{\mathrm{a}}$ \\
\hline CB phenotype & 1.42 & $0.70-2.87$ & 0.32 & $-{ }^{\mathrm{a}}$ & $-{ }^{\mathrm{a}}$ & $-^{\mathrm{a}}$ \\
\hline Emphysema phenotype & 0.87 & $0.43-1.79$ & 0.72 & $-{ }^{\mathrm{a}}$ & $-{ }^{\mathrm{a}}$ & $-^{\mathrm{a}}$ \\
\hline ACOS phenotype & 0.32 & $0.04-2.44$ & 0.27 & $-^{\mathrm{a}}$ & $-^{\mathrm{a}}$ & $-^{\mathrm{a}}$ \\
\hline Frequent exacerbator phenotype & 2.09 & $1.04-4.21$ & 0.03 & 1.96 & $0.97-3.95$ & 0.05 \\
\hline GOLD stage & 1.07 & $0.68-1.67$ & 0.76 & $-{ }^{\mathrm{a}}$ & $-^{\mathrm{a}}$ & $-^{\mathrm{a}}$ \\
\hline
\end{tabular}

$\mathrm{CB}$, chronic bronchitis; ACOS, asthma-COPD overlap syndrome.

${ }^{a}$ Variables not included in the final model.

Table 5. Univariate and multivariate logistic regression analysis for peripheral vascular disease

\begin{tabular}{|c|c|c|c|c|c|c|}
\hline \multirow[t]{2}{*}{ Variable } & \multicolumn{3}{|c|}{ Univariate analysis } & \multicolumn{3}{|c|}{ Multivariate analysis } \\
\hline & OR & $95 \% \mathrm{CI}$ & $p$ & OR & $95 \% \mathrm{CI}$ & $p$ \\
\hline Age & 1.02 & $1.00-1.05$ & 0.04 & 1.03 & $1.00-1.06$ & 0.02 \\
\hline Male sex & 4.61 & $1.69-12.54$ & 0.02 & $-^{\mathrm{a}}$ & $-{ }^{\mathrm{a}}$ & $-{ }^{\mathrm{a}}$ \\
\hline Biomass exposure & 0.28 & $0.11-0.71$ & $<0.01$ & $-{ }^{a}$ & $-{ }^{\mathrm{a}}$ & $-{ }^{\mathrm{a}}$ \\
\hline $\mathrm{CB}$ phenotype & 0.94 & $0.57-1.55$ & 0.81 & $-{ }^{\mathrm{a}}$ & $-{ }^{\mathrm{a}}$ & $--^{\mathrm{a}}$ \\
\hline Emphysema phenotype & 1.26 & $0.76-2.08$ & 0.35 & $-{ }^{\mathrm{a}}$ & $-{ }^{\mathrm{a}}$ & $-^{\mathrm{a}}$ \\
\hline ACOS phenotype & 0.48 & $0.14-1.58$ & 0.23 & $-{ }^{\mathrm{a}}$ & $-{ }^{\mathrm{a}}$ & $-{ }^{\mathrm{a}}$ \\
\hline Frequent exacerbator phenotype & 0.84 & $0.49-1.44$ & 0.53 & $-{ }^{\mathrm{a}}$ & $-{ }^{\mathrm{a}}$ & $-{ }^{\mathrm{a}}$ \\
\hline GOLD stage & 0.90 & $0.65-1.25$ & 0.55 & $-^{\mathrm{a}}$ & $-^{\mathrm{a}}$ & $-^{\mathrm{a}}$ \\
\hline
\end{tabular}

$\mathrm{CB}$, chronic bronchitis; ACOS, asthma-COPD overlap syndrome.

a Variables not included in the final model. 
dung burning exhibited predominantly increased neutrophil and macrophage chemokine [24]. However, with wood smoke exposure, mice showed raised eosinophil cytokines [24]. Consequently, the distribution of comorbidities might be different in distinct geographic areas, depending on the kind of fuels employed.

Our study has a number of strengths, including the fact that we were able to include a relatively large proportion of male subjects with B-COPD. Most studies of B-COPD have been performed mainly or exclusively in women who, for socioeconomical reasons, are more frequently exposed to biomass smoke while cooking. Biomass kitchens have also been used in our area as a home heating system, and families usually gathered around the kitchen in wintertime. Thus, many male subjects were exposed to biomass smoke. Therefore, our study provides the opportunity to test the interactions between sex and other variables in B-COPD. Another strength is that, unlike some studies carried out using administrative databases, the diagnosis of COPD was objectively confirmed with lung function testing, and we were able to include explaining variables, such as severity of the ventilatory obstruction and the COPD phenotype, that in previous studies have been found to be associated with comorbidities $[5,6]$.

Conversely, some limitations of the study must be pointed out. We have not investigated all possible comorbidities associated with COPD, but only those major diseases included in the Charlson and COTE indices. Some comorbidities, like arterial hypertension, or other arrhythmias than atrial fibrillation were not systematically registered. This might partially explain the lower-thanexpected prevalence of cardiovascular disease. However, the strongest association between having COPD and a past diagnosis of cardiovascular disease is seen in younger patients, with a decrease in odds in older age groups [25], and the mean age of our patients was relatively high (about 70 years).

In addition, there might have been some overlap between the B-COPD and T-COPD groups because some patients in the T-COPD group might also have been exposed to biomass smoke. However, the differences in age, body mass index, $\mathrm{FEV}_{1}$, and prevalence of emphysema phenotype between $\mathrm{B}-\mathrm{COPD}$ and $\mathrm{T}-\mathrm{COPD}$ are congruent with previous studies $[9,26]$. The retrospective nature of the study implies the possibility that some significant explanatory variables might have been missed for the multivariate analysis. The statistical power of the study for the main variable studied was slightly below the optimal value of $80 \%$, and this raises the possibility that the sample size might be insufficient to test all interaction ef- fects. Regarding peptic ulcer disease, there were only 33 outcome events and, therefore, the model had few outcome events per explanatory variable. This fact entails the risk of overfitting of the model for this particular variable and, therefore, the risk estimates might be unreliable for this particular comorbidity [27]. Due to the retrospective nature of the study, the cumulative exposure to biomass smoke could not be calculated precisely and, consequently, we could not test a dose-response relationship, which would have increased the biological plausibility of the associations found.

We detected a higher prevalence of the ACOS phenotype in the B-COPD group that would be congruent with an increased Th2 response. However, the ACOS definition was based on a non-validated expert consensus document [28], and it is highly debatable whether this definition is appropriate for B-COPD [29]. Study subjects were selected from a hospital-based COPD clinic, so there is the possibility of selection bias. Actually, there were few patients with mild (GOLD 1) disease and this limits the generalizability of the results to other settings. Furthermore, socioeconomic conditions might be different for B-COPD and T-COPD. Consequently, lifestyle or environmental variables might have biased the results to some degree.

In conclusion, we have found a different distribution of comorbidities for patients with B-COPD and T-COPD, with a significant lower risk for suffering ischemic heart disease for patients exposed to biomass fuels. These results suggest that the systemic effects of biomass smoke are different to those of tobacco. However, due to the limitations of size and design of the study, these findings must be taken with precaution, and should serve mainly as the basis for future research.

\section{Disclosure Statement}

The authors have no conflicts of interest to disclose.

\section{References}

1 World Health Organization: World Health Statistics. 2008. http://www.who.int/whosis/ whostat/EN_WHS08_Full.pdf?ua=1. (accessed November 16, 2016).

2 Global Strategy for the Diagnosis, Management and Prevention of COPD, Global Initiative for Chronic Obstructive Lung Disease (GOLD) 2017. http://goldcopd.org/. (accessed January 18, 2017).

Comorbidities in Biomass COPD 
3 Feary JR, Rodrigues LC, Smith CJ, Hubbard RB, Gibson JE: Prevalence of major comorbidities in subjects with COPD and incidence of myocardial infarction and stroke: a comprehensive analysis using data from primary care. Thorax 2010;65:956-962.

4 Sode BF, Dahl M, Nordestgaard BG: Myocardial infarction and other co-morbidities in patients with chronic obstructive pulmonary disease: a Danish nationwide study of 7.4 million individuals. Eur Heart J 2011;32:23652375.

5 Dal Negro RW, Bonadiman L, Turco P: Prevalence of different comorbidities in COPD patients by gender and GOLD stage. Multidiscip Respir Med 2015;10:24.

6 Camiciottoli G, Bigazzi F, Magni C, Bonti V, Diciotti S, Bartolucci M, Mascalchi M, Pistolesi M: Prevalence of comorbidities according to predominant phenotype and severity of chronic obstructive pulmonary disease. Int J Chron Obstruct Pulmon Dis 2016;11:22292236.

7 Salvi S, Barnes PJ: Is exposure to biomass smoke the biggest risk factor for COPD globally? Chest 2010;138:3-6.

8 Ramírez-Venegas A, Sansores RH, QuintanaCarrillo RH, Velázquez-Uncal M, Hernández-Zenteno RJ, Sánchez-Romero C, Velázquez-Montero A, Flores-Trujillo F: FEV1 decline in patients with chronic obstructive pulmonary disease associated with biomass exposure. Am J Respir Crit Care Med 2014; 190:996-1002.

9 Camp PG, Ramírez-Venegas A, Sansores RH, Alva LF, McDougall JE, Sin DD, Paré PD, Müller NL, Silva CI, Rojas CE, Coxson HO: COPD phenotypes in biomass smoke- versus tobacco smoke-exposed Mexican women. Eur Respir J 2014;43:725-734.

10 Golpe R, Sanjuán-López P, Cano-Jiménez E, Castro-Añón O, Pérez-de-Llano LA: Distribution of clinical phenotypes in patients with chronic obstructive pulmonary disease caused by biomass and tobacco smoke. Arch Bronconeumol 2014;50:318-324.

11 Hillas G, Perlikos F, Tsiligianni I, Tzanakis N: Managing comorbidities in COPD. Int J Chron Obstruct Pulmon Dis 2015;10:95-109.

12 Solleiro-Villavicencio H, Quintana-Carrillo $\mathrm{R}$, Falfán-Valencia R, Vargas-Rojas MI: Chronic obstructive pulmonary disease in- duced by exposure to biomass smoke is associated with a Th2 cytokine production profile. Clin Immunol 2015;161:150-155.

13 Miravitlles M, Soler-Cataluña JJ, Calle M, Molina J, Almagro P, Quintano JA, Riesco JA, Trigueros JA, Piñera P, Simón A, LópezCampos JL, Soriano JB, Ancochea J: Guía española de la EPOC (GesEPOC). Tratamiento farmacológico de la EPOC estable. Arch Bronconeumol 2012;48:247-257.

14 Hurst JR, Vestbo J, Anzueto A, Locantore N, Müllerova H, Tal-Singer R, Miller B, Lomas DA, Agustí A, Macnee W, Calverley P, Rennard S, Wouters EF, Wedzicha JA; ECLIPSE investigators: Susceptibility to exacerbation in chronic obstructive pulmonary disease. $\mathrm{N}$ Engl J Med 2010;363:1128-1138.

15 Charlson ME, Pompei P, Ales K, McKenzie CR: A new method of classifying prognostic comorbidity in longitudinal studies: development and validation. J Chronic Dis 1987;40: 373-383.

16 Divo M, Cote C, de Torres JP, Casanova C, Marín JM, Pinto-Plata V, Zulueta J, Cabrera C, Zagaceta J, Hunninghake G, Celli B; BODE collaborative group: Comorbidities and risk of mortality in patients with chronic obstructive pulmonary disease. Am J Respir Crit Care Med 2012;186:155-161.

17 Ahluwalia SC, Gross CP, Chaudhry SI, LeoSummers L, Van Ness PH, Fried TR: Change in comorbidity prevalence with advancing age among persons with heart failure. J Gen Intern Med 2011;26:1145-1151.

18 Rosner B: Fundamentals of Biostatistics, ed 7. Boston, Brooks/Cole, 2001, pp 301-304, 381390.

19 Orozco-Levi M, García Aymerich J, Villar J, Ramírez-Sarmiento A, Antó JM, Gea J: Wood smoke exposure and risk of chronic obstructive pulmonary disease. Eur Respir J 2006;27: 542-546.

20 Sin DD, Man SF: Why are patients with chronic obstructive pulmonary disease at increased risk of cardiovascular diseases? The potential role of systemic inflammation in chronic obstructive pulmonary disease. Circulation 2003;107:1514-1519.

21 Celli BR, Locantore N, Yates J, Tal-Singer R, Miller BE, Bakke P, Calverley P, Coxson H, Crim C, Edwards LD, Lomas DA, Duvoix A, MacNee W, Rennard S, Silverman E, Vestbo
J, Wouters E, Agustí A: Inflammatory biomarkers improve clinical prediction of mortality in chronic obstructive pulmonary disease. Am J Respir Crit Care Med 2012;185: 1065-1072.

22 Liu Y, Berthier-Schaad Y, Fallin MD, Fink NE, Tracy RP, Klag MJ, Smith MW, Coresh J: IL-6 haplotypes, inflammation and risk for cardiovascular disease in a multiethnic dialysis cohort. J Am Soc Nephrol 2006;17:863870.

23 Apostolakis S, Vogiatzi K, Amanatidou V, Spanidos DA: Interleukin 8 and cardiovascular disease. Cardiovasc Res 2009;84:353-360.

24 Sussan TE, Ingole V, Kim JH, McCormick S, Negherbon J, Fallica J, Akulian J, Yarmus L, Feller-Kopman D, Wills-Karp M, Horton MR, Breysse PN, Agrawal A, Jukevar S, Salvi S, Biswal S: Source of biomass cooking fuel determines pulmonary response to household air pollution. Am J Respir Cell Mol Biol 2014;50:538-548.

25 Feary JR, Rodrigues LC, Smith CJ, Hubbard RB, Gibson JE: Prevalence of major comorbidities in subjects with COPD and incidence of myocardial infarction and stroke: a comprehensive analysis using data from primary care. Thorax 2010;65:956-962.

26 Ramirez-Venegas A, Sansores RH, Pérez-Padilla R, Regalado J, Velázquez A, Sánchez C, Mayar ME: Survival of patients with chronic obstructive pulmonary disease due to biomass smoke and tobacco. Am J Respir Crit Care Med 2006;173:393-397.

27 Concato J, Feinstein AR, Holford TR: The risk of determining risk with multivariable models. Ann Intern Med 1993;118:201-210.

28 Soler-Cataluña JJ, Cosío B, Izquierdo JL, López-Campos JL, Marín JM, Agüero R, Baloira A, Carrizo S, Esteban C, Galdiz JB, González MC, Miravitlles M, Monsó E, Montemayor T, Morera J, Ortega F, Peces-Barba G, Puente L, Rodríguez JM, Sala E, Sauleda J, Soriano JB, Viejo JL: Consensus document on the overlap phenotype COPD-asthma in COPD. Arch Bronconeumol 2012;48:331337.

29 Golpe R, Pérez-de-Llano LA: Are the diagnostic criteria for asthma-COPD overlap syndrome appropriate in biomass smoke-induced chronic obstructive pulmonary disease? Arch Bronconeumol 2016;52:110. 